\title{
Light Control and Watering System in Greenhouse for The Cultivation of Chrysanthemum Sp
}

\author{
Adam Faroqi ${ }^{1}$, Muhammad Ali Ramdhani ${ }^{2}$, Muhammad Fahmi Amrillah ${ }^{3}$, Lia Kamelia ${ }^{4}$, \\ Eneng Nuraeni ${ }^{5}$ \\ 1,3,4 Department of Electrical Engineering, UIN Sunan Gunung Djati Bandung, \\ Jl, A. H. Nasution No. 105, Bandung, Indonesia \\ ${ }^{2}$ Department of Informatics, UIN Sunan Gunung Djati Bandung, \\ Jl, A. H. Nasution No. 105, Bandung, Indonesia \\ ${ }^{5}$ Department of Constitutional Law, UIN Sunan Gunung Djati Bandung, \\ J1, A. H. Nasution No. 105, Bandung, Indonesia
}

\begin{tabular}{l}
\hline Article Info \\
\hline Article history: \\
Received Apr 29, 2018 \\
Revised Jul 19, 2018 \\
Accepted Aug 21, 2018 \\
\hline
\end{tabular}

Keywords:

Arduino mega 2560

Chrysanthemum sp

DHT-22

Greenhouse

SEN0057

\begin{abstract}
Chrysanthemum (Chrysanthemum Sp) is sensitive to temperature and humidity. Greenhouse is an appropriate planting medium since temperature and humidity can be engineered there. This article presents the design of systems using DHT-22 and SEN0057 sensors. Real Time Clock (RTC) is used for providing timing input and functions as an extra light intensity timer. Arduino Mega 2560 is used as a microcontroller functioning to receive the results of sensor measurement and to give output instructions to condition the temperature and humidity. The testing on chrysanthemum Sp placed inside the greenhouse equipped with the system for 7 days shows an increase of height of $3.7 \mathrm{~cm}$. As for chrysanthemum $\mathrm{Sp}$ placed outside the greenhouse equipped with the system for 7 days, there is an increase of height of $0,2 \mathrm{~cm}$. These greenhouse light control and Watering systems can engineer the temperature and humidity in accordance with the needs of chrysanthemum Sp cultivation in the greenhouse.
\end{abstract}

Copyright $@ 2018$ Institute of Advanced Engineering and Science. All rights reserved.

\section{Corresponding Author:}

Adam Faroqi,

Department of Electrical Engineering,

UIN Sunan Gunung Djati Bandung,

Jl, A. H. Nasution No. 105,

Bandung, Indonesia.

Email: adam.faroqi@uinsgd.ac.id

\section{INTRODUCTION}

Technology is made to improve the quality of human life [1]-[3], one of the technology that can be used to help the effectiveness and efficiency of farming is controlilng climate with greenhouse. Greenhouse is a place used to maintain the climate control in a room [4]. The structure of greenhouse can be perfectly enclosed to protect plants and to promote the growth of crops [5]. Greenhouse is used to maintain the room temperature stability, and soil moisture and acid levels to suit the needs of plants, thus the plant can grow well [6]. To work properly, greenhouse has some parameters to consider, namely: room temperature, soil temperature, humidity, watering system, light intensity, and ventilation [7]. Due to its function, greenhouse is widely used to develop plants sensitive to the room temperature and humidity, one of which is chrysanthemum (Chrysanthemum Sp).

Chrysanthemum is a plant that cannot stand puddles and is less suited to direct sunlight and direct rainwater splashing. Therefore, it is recommended to cultivate Chrysanthemum in a greenhouse to avoid direct sunlight and rainwater. Chrysanthemum requires longer lighting than other plants do. If chrysanthemum gets less than 12 hours of light, its vegetative phase (growth of height) does not last long 
and cause the height of chrysanthemum at harvest time only about $40 \mathrm{~cm}$. To maintain the vegetative phase well, it is necessary to add the light at night that is 70-100 lux. Thus it will make chrysanthemum reach the expected height, i.e. more than $76 \mathrm{~cm}$ or increase of 6-7 $\mathrm{cm}$ each week [8].

Research on humidity and temperature control in greenhouse has been mostly done for various plants [9], [10]. This study focuses on designing a greenhouse environmental control system, capable of controlling temperature, humidity, and lighting systems for chrysanthemum cultivation.

\section{MATERIALS AND METHOD}

\subsection{Materials}

a. Sensor DHT-22

DHT-22 Sensor is a digital sensor that can measure the air temperature and humidity [8]. The Specification of DHT-22 sensor (Figure 1) is presented in Table 1.

Table 1. The Specification of DHT22 Sensor

\begin{tabular}{ll}
\hline Sensor & $\mathrm{DHT} 22$ \\
\hline Supply Voltage & $5 \mathrm{~V}$ \\
Temperature Range & $-40-80^{\circ} \mathrm{C} /$ resolution $0.1^{\circ} \mathrm{C} /$ error \\
& $< \pm 0.5^{\circ} \mathrm{C}$ \\
Humidity Range & $0-100 \% \mathrm{RH} /$ resolution $0.1 \% \mathrm{RH} /$ \\
& error $\pm 2 \% \mathrm{RH}$. \\
Temperature & Condition: $1 / \mathrm{e}(63 \%) \mathrm{Min} 6 \mathrm{~s} \mathrm{Max}$ \\
Response & $20 \mathrm{~s}$ \\
Humidity Response & Condition: $1 / \mathrm{e}(63 \%) 25^{\circ} \mathrm{C}, 1 \mathrm{~m} / \mathrm{s}$ in \\
Rime & the air. \\
Interface Sequence & VCC, GND, Output. \\
\hline
\end{tabular}

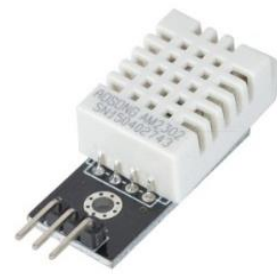

Interface Sequence VCC, GND, Output.

Figure 1. DHT22 Sensor Module [11]

b. Sensor SEN0057

SEN0057 sensor is used to measure the soil moisture. The Specification of SEN0057 sensor (Figure 2), is presented in Table 2.

Table 2. The Specification of SEN0057 Sensor

\begin{tabular}{ll}
\hline Sensor & SEN0057 \\
\hline Power Supply & $3.3 \mathrm{~V}$ or $5 \mathrm{~V}$ \\
Output Voltage Signal & $0-4.2 \mathrm{~V}$ \\
Current & $35 \mathrm{~mA}$ \\
Pin Definition & Analog Output, GND, Power \\
Size & $60 \times 20 \times 5 \mathrm{~cm}$ \\
\hline
\end{tabular}

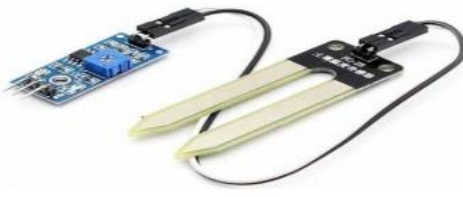

Figure 2. SEN0057 Sensor [12]

\section{c. Arduino Mega 2560}

Arduino Mega 2560 is a microcontroller device using ATmega2560 [13]. This module has the devices needed to program a microcontroller such as a USB cable and power supply with adapters or batteries. The specification of Arduino Mega 2560 (Figure 3) is presented in Table 3.

Table 3. The Specification of Arduino Mega 2560

\begin{tabular}{ll}
\hline Module & Arduino Mega 2560 \\
\hline Microcontroller & ATmega2560 \\
Operating Voltage & $5 \mathrm{~V}$ \\
Input voltage (recommended) & $7-12 \mathrm{~V}$ \\
Input voltage (limits) & $6-20 \mathrm{~V}$ \\
Digital I/O Pins & 54 (15 PWM output) \\
Analog Input Pins & 16 \\
DC current for I/O pin & $40 \mathrm{~mA}$ \\
DC current for 3.3 V pin & $50 \mathrm{~mA}$ \\
Flash Memory & $256 \mathrm{~KB}$ (of which $8 \mathrm{~KB}$ \\
& used by boot loader) \\
SRAM & $8 \mathrm{~KB}$ \\
EEPROM & $4 \mathrm{~KB}$ \\
\hline
\end{tabular}

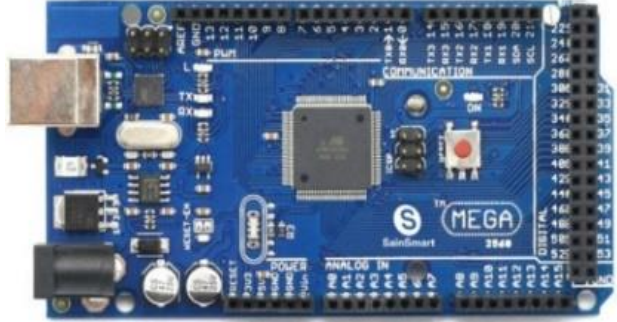

Figure 3. Arduino Mega 2560 [14] 


\section{d. Chrysanthemum.}

Chrysanthemum (Chrysanthemum Sp) belongs to family Compositae originating from China (Figure 4). It grows well in medium to high lands ranging from 700 to 1200 masl [15]. The characteristics of the requirement for ideal chrysanthemum growth are presented in Table 4 .

\begin{tabular}{ll}
\multicolumn{2}{c}{ Table 4. The Specification of SEN0057 Sensor } \\
\hline Flower name & Chrysanths (Chrysanthemum Sp) \\
\hline Crop & $700-1200$ masl \\
$\begin{array}{l}\text { Geographical } \\
\text { Location }\end{array}$ & \\
Ideal & - $22-28^{\circ} \mathrm{C}$ (Early growing phase and \\
Temperature & vegetative phase) \\
Requirement & - $16-18^{\circ} \mathrm{C}$ (Flowering phase) \\
Ideal & - $90-95 \%$ (Early growing phase) \\
Humidity & - $70-85 \%$ (Vegetative phase and \\
Requirement & Flowering phase) \\
Ideal & - Clay, sandy, fertile, loose \\
Soil & pH $5,5-6,5$ \\
Characteristics &
\end{tabular}

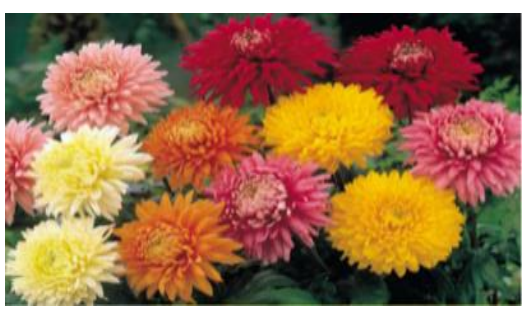

Figure 4. Chrysanthemum sp[8]

\section{e. Greenhouse}

The use of greenhouse is to protect plants from environmental conditions such as temperature, air humidity, and adjustable light intensity [16]. The use of greenhouse will greatly affect the microclimate conditions different from the climate in the surrounding environment [15].

\subsection{Menthod}

The designed system is light control automation and greenhouse for humidity-sensor-based chrysanthemum cultivation following the flowchart as shown in Figure 5. The greenhouse light control and watering system devices in this study use a 9 volt voltage to meet the expected performance. The main system or controller of these devices uses Arduino Mega 2560 module. Inputs received by Arduino Mega 2560 consist of a DHT-22 sensor module functioning to measure the air temperature and humidity, and a SEN0057 sensor module functioning to measure the soil moisture. In addition, Real-Time Clock (RTC) is used as the input functioning to provide the timer used to enable the schedule of high or low lights. These devices have several outputs with their own functions.

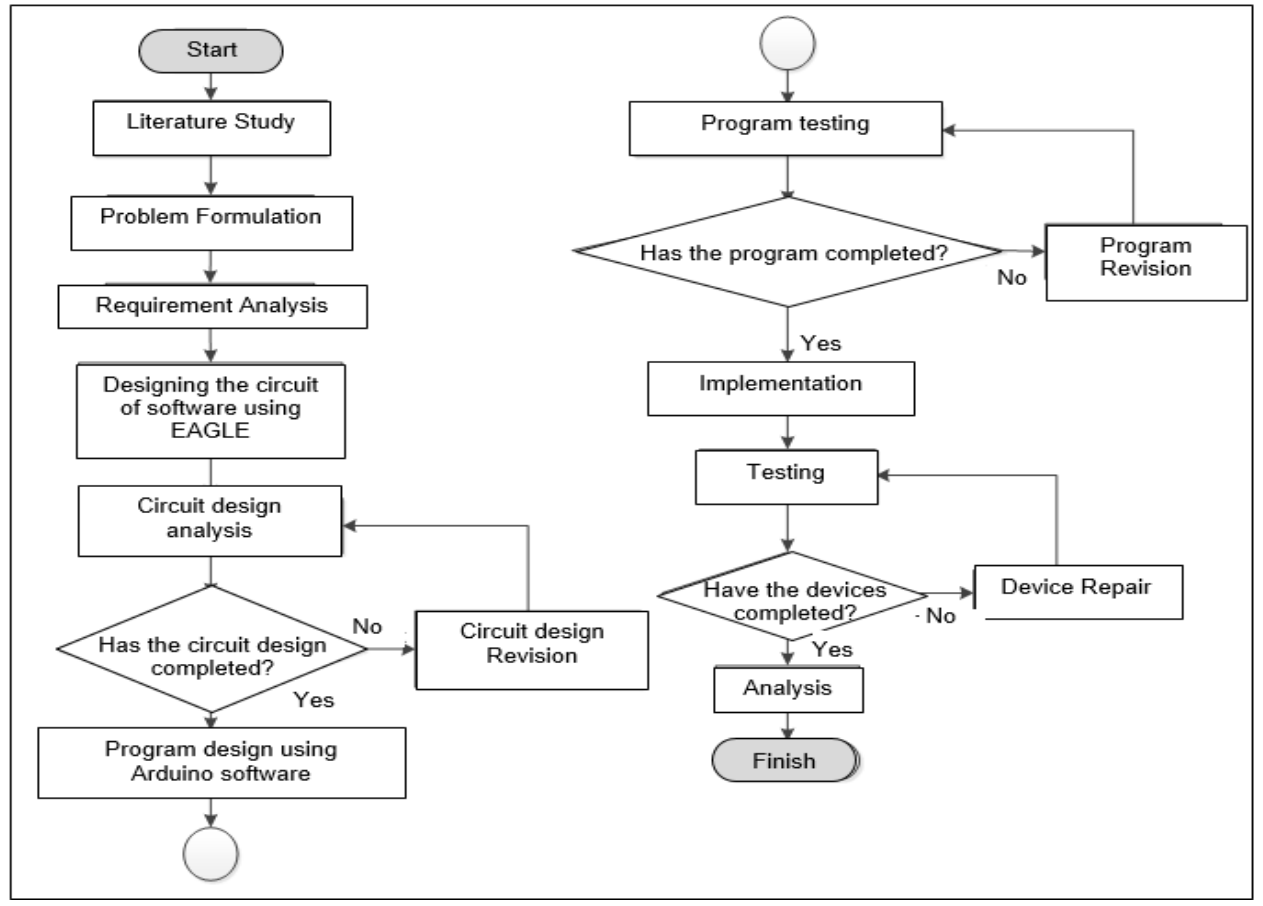

Figure 5. Research Flowchart 
The LCD functions to display the results of measurement made by DHT-22 and SEN0057 sensor modules to make it easy to identify. The output is an actuator or tools that can be instructed by the Arduino Mega 2560 module in response to inputs given by the sensor. The output of these tools consists of heating lamp, lamp, blower, dry fan and water pump. The block diagram of the design of tools can be seen in Figure 6.

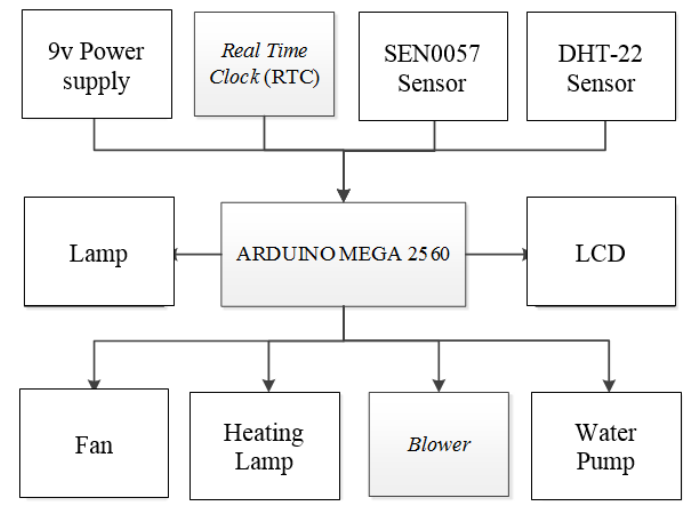

Figure 6. The block diagram of greenhouse light control and watering system

\section{RESULTS AND DISCUSSION}

\subsection{Implementation}

After the design stage in the form of circuit scheme and overall design of the main system program code, it is continued to the stage of assembling devices. This stage is carried out by designing PCB circuit and design using software, EAGLE, and then, printing the PCB used in the making of devices for monitoring the light control and watering system in the greenhouse for chrysanthemum cultivation. Printed PCB can be seen in Figure 7.

PCB with installed components can be seen in Figure 8. The PCB is then connected with Arduino board and relay board using cable as in Figure 9. It is done in order that the devices work in accordance with the intended specifications.

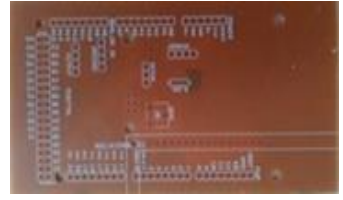

(a) Top View

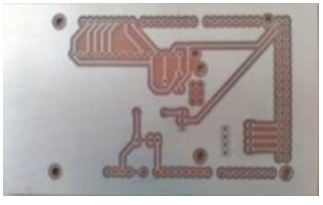

(b) Bottom View

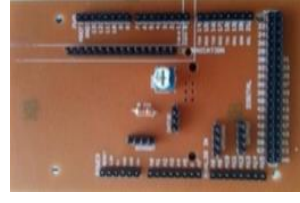

(a) PCB Top View

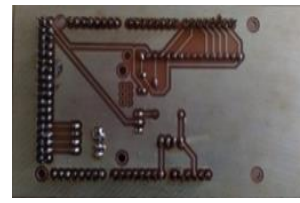

(b) PCB Bottom View

Figure 7. PCB

Figure 8. PCB with components installed

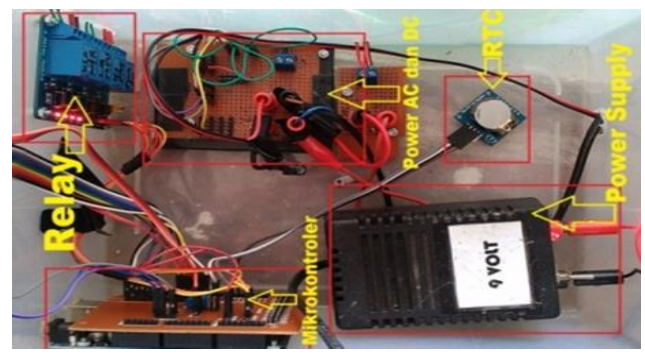

Figure 9. Hardware circuit of the main system 


\subsection{Circuit Testing and Analysis}

Circuit testing is done to check whether the circuit works as expected. The circuit is considered to work well if all components connected by it are on and work properly, including: sensor module, LCD, Arduino, relay, fan, lamp, pump, blower and other supporting components. Based on the testing result, all components connected by the circuit are on and work properly, indicated by one of the main indicators, i.e. the LED that lights up well.

\subsection{DHT-22 Sensor Testing and Analysis}

DHT-22 sensor module works to measure the air temperature and humidity in the greenhouse. Based on the testing result, the data obtained by the DHT-22 and calibrator sensors are not significantly different (average difference are $\pm 0.0875^{\circ} \mathrm{C}$ for air temperature, and $\pm 3.75 \%$ for air humidity).

\subsection{SEN0057 Sensor Testing and Analysis}

At this stage SEN0057 sensor is tested to ensure the sensor works properly. Sensor SEN0057 works to measure the soil moisture used as a medium for growing chrysanthemum. verification of the accuracy of soil moisture measurements by SEN0057 can be seen in Table 5. The testing result show that the data obtained by the two devices are significantly different. The difference is expected because of differences in methods used by both devices. SEN0057 uses highly accurate digital method with small calculation errors since the digital method has the least probability to get disturbance from noise. Meanwhile, the calibrator used in this study uses analog method whose accuracy is likely to be influenced by noise, causing high probability of error in its calculation.

Table 5. The Testing Results of SEN0057 Sensor and Calibrator

\begin{tabular}{ccccc}
\hline No & Testing Time & SEN0057 & $\begin{array}{c}\text { Soil Moisture }(\%) \\
\text { Calibrator }\end{array}$ & Difference \\
\hline 1 & 05.00 & 100 & 92 & 8 \\
2 & 05.24 & 100 & 92 & 8 \\
3 & 17.14 & 95 & 87 & 8 \\
4 & 17.51 & 94 & 85 & 9 \\
5 & 21.40 & 90 & 82 & 8 \\
6 & 22.00 & 90 & 82 & 8 \\
7 & 22.12 & 89 & 80 & 9 \\
8 & 22.36 & 89 & 80 & 9.375 \\
\hline
\end{tabular}

\subsection{System Performance Testing and Analysis}

Testing and analysis of the performance of light control and watering system automation system in greenhouse for chrysanthemum cultivation is conducted to ensure the system works according to the initial specification.

System performance testing is done in various conditions. Response time is the time taken to stabilize the condition from not ideal to ideal. In the first testing, the outputs, lamp and pump, are on while the blower and fan are not. This is in line with the initial reference, namely if the air temperature is below $22^{\circ} \mathrm{C}$, the light is on and if the soil moisture is below $70 \%$, the pump is on, while the fan and blower are not because the temperature and humidity do not exceed $28^{\circ} \mathrm{C}$ for the fan and are below $70 \%$ for the blower. On the other hand, the fan and blower are on while the lamp and pump are not in the second testing since it is given a condition as in Table 6.

Table 6. The Results of System Performance Testing Affected by Sensors in Various Conditions

\begin{tabular}{|c|c|c|c|c|c|c|c|}
\hline \multirow{2}{*}{ No } & \multirow{2}{*}{$\begin{array}{c}\text { Air } \\
\text { Temperature } \\
\left({ }^{\circ} \mathrm{C}\right)\end{array}$} & \multirow{2}{*}{$\begin{array}{l}\text { Air Humidity } \\
\qquad \%)\end{array}$} & \multirow{2}{*}{$\begin{array}{c}\text { Soil Moisture } \\
(\%)\end{array}$} & \multicolumn{4}{|c|}{ On/Off condition \& Response time (Second/s) } \\
\hline & & & & Fan & Blower & Heating Lamp & Pump \\
\hline 1 & 21.0 & 75 & 67 & - & - & $\sqrt{(90 s)}$ & $\sqrt{(5 s)}$ \\
\hline 2 & 29.0 & 55 & 80 & $\sqrt{ }(120 \mathrm{~s})$ & $\sqrt{ }(300 \mathrm{~s})$ & - & - \\
\hline 3 & 28.0 & 70 & 90 & - & - & - & - \\
\hline 4 & 21.9 & 60 & 55 & - & $\sqrt{ }(200 s)$ & $\sqrt{ }(30 \mathrm{~s})$ & $\sqrt{ }(10 \mathrm{~s})$ \\
\hline 5 & 20.0 & 80 & 72 & - & - & $\sqrt{ }(180 \mathrm{~s})$ & - \\
\hline 6 & 27.0 & 80 & 60 & - & - & - & $\sqrt{ }(7 \mathrm{~s})$ \\
\hline 7 & 28.0 & 60 & 90 & - & $\sqrt{ }(210 \mathrm{~s})$ & - & - \\
\hline 8 & 30.0 & 75 & 85 & $\sqrt{ }(240 \mathrm{~s})$ & - & - & - \\
\hline
\end{tabular}


In the third testing, the outputs are off. This is because the condition of air temperature, air humidity and soil moisture is in stable condition or in accordance with the requirement of the growth of chrysanthemum i.e. air temperature between $22-28^{\circ} \mathrm{C}$, air humidity $70-100 \%$ and soil moisture $70-100 \%$. In the fourth testing, the blower, the lamp and the pump are on because the condition has been met according to the initial reference. Meanwhile, the fan is off because its condition will be inversely proportional to the lamp's, namely, when the fan is on, the lamp must be off, and vice versa. This is because the fan is related to too high temperature while the lamp is related to too low temperature.

Testing and analysis is done not only for outputs affected by the sensors, but also for the system performance influenced by Real-Time Clock (RTC): if the time is at 19:00 to 23:59, the lamp will be on or in a high condition (1); if the time is not at 19:00 to 23:59, the lamp will be off or in a low condition (0).

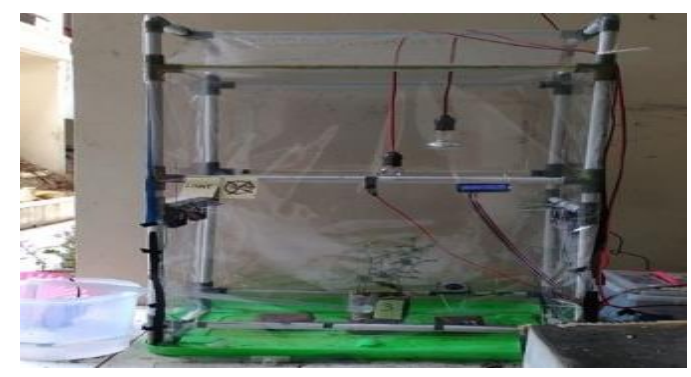

Figure 10. Greenhouse and light control system and watering system for the cultivation of chrysanthemum

The testing and analysis that have been described show that each output is on in accordance with the reference that has been set, therefore, it can be concluded that the system performance has been in accordance with the initial specification and can be implemented in greenhouse for chrysanthemum cultivation.

\subsection{System Implementation Testing and Analysis}

System implementation testing is done to know the extent to which the system can work well and properly for chrysanthemum cultivation. The result of this testing is presented in Table 7. This testing has been conducted for seven consecutive days with the object of observation focusing only on the height increase of chrysanthemum each day. It is done using two chrysanthemums placed in pots with different placement. Pot 3 is placed inside the greenhouse equipped with the system, while Pot 6 (control) is placed outside the greenhouse as well as outside the system created.

Table 7 shows that the height of chrysanthemum placed in Pot 3 placed inside the greenhouse equipped with the system increases of $3.7 \mathrm{~cm}$ and its average daily increase is $0.616 \mathrm{~cm}$. Meanwhile, the height of chrysanthemum placed in pot 6 which is placed outside the greenhouse and outside the system increases of $0.2 \mathrm{~cm}$ and its average daily increase is $0.033 \mathrm{~cm}$. The comparison of height growth of chrysanthemums can be seen in Figure 11 and Figure 12.

Table 7. The Results of System Implementation Testing

\begin{tabular}{|c|c|c|c|c|}
\hline \multirow[b]{2}{*}{ Day- } & \multicolumn{2}{|c|}{ Plant Height $(\mathrm{cm})$} & \multicolumn{2}{|c|}{ Plant Height Increase $(\mathrm{cm})$} \\
\hline & $\begin{array}{c}\text { Pot } 6 \\
\text { (Outside the system) }\end{array}$ & $\begin{array}{c}\text { Pot } 3 \\
\text { (inside the system) }\end{array}$ & $\begin{array}{c}\text { Pot } 6 \\
\text { (Outside the system) }\end{array}$ & $\begin{array}{c}\text { Pot } 3 \\
\text { (inside the system) }\end{array}$ \\
\hline 1. & 21 & 21.3 & - & - \\
\hline 2. & 21 & 21.9 & 0.0 & 0.6 \\
\hline 3. & 21 & 22.6 & 0.0 & 0.7 \\
\hline 4. & 21.1 & 23.4 & 0.1 & 0.8 \\
\hline 5. & 21.1 & 24.0 & 0.0 & 0.6 \\
\hline 6. & 21.1 & 24.6 & 0.0 & 0.6 \\
\hline 7. & 21.2 & 25.0 & 0.1 & 0.4 \\
\hline \multicolumn{2}{|c|}{ Average Daily Height Increase } & & 0.033 & 0.616 \\
\hline
\end{tabular}

The significant difference in the height increase of the chrysanthemums placed in the two pots is due to the different placement. Pot 3 is placed inside the greenhouse equipped with a system to support the growth of chrysanthemum according to the characteristics adapted for, from temperatures to additional light. Based on the literature that has been described in the previous chapter, it is said that chrysanthemum requires 
longer lighting for the process of height growth, namely more than 12 hours to get a maximum height i.e. about 6-7 cm per week [17]. In the system, additional light from the lamp is set automatically for five hours. In addition, the air temperature, air humidity and humidity of the plant are engineered by the system by means of automation to adapt to the characteristics required by chrysanthemum. Meanwhile, pot 6 is placed outside the greenhouse and is not equipped with the system so that the light, air temperature, air humidity and soil moisture are not engineered there. In other words, it follows the natural conditions resulting in environmental conditions that are not in accordance with the characteristics of chrysanthemum, thus causing the growth of chrysanthemum not optimal.

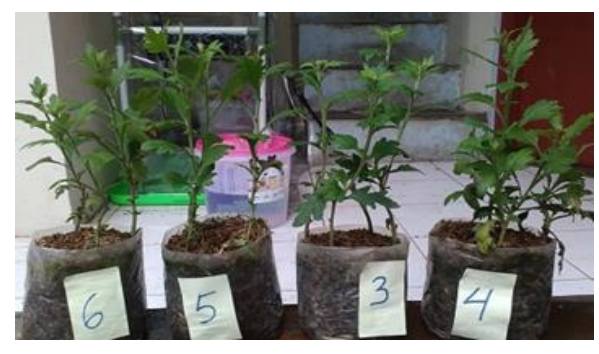

Figure 11. The plant condition before the testing (plants used are no. 6 and 3)

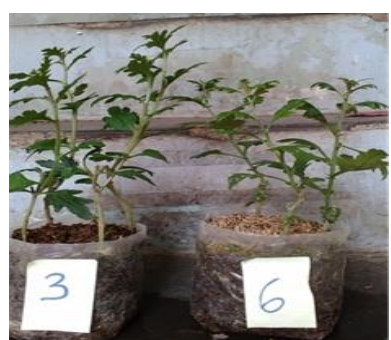

Figure 12. The plant condition after the testing

\section{CONCLUSION}

Based on the testing results on the function and performance of the sensors, it can be concluded that DHT-22 sensor can measure the temperature and humidity of the air, and SEN0057 sensor can measure soil moisture. Moreover, according to the result of testing and analysis of the design and development of the system, it can be concluded that the system works well according to the initial specification because the heater lamp is on when the temperature is lower than $22^{\circ} \mathrm{C}$, the fan is on when the temperature is higher than $28^{\circ} \mathrm{C}$, the blower is on when the air humidity is less than $70 \%$, the pump is on when the soil moisture is less than $70 \%$, and the lamp for additional light is on at 19.00-23.59 WIB. The system performance testing on the process of height increase shows a significant change with the height increasing of $3.7 \mathrm{~cm}$ in 7 days, compared to the height increase of chrysanthemum treating without the system and outside the greenhouse, namely, $0.2 \mathrm{~cm}$ in 7 days.

\section{REFERENCES}

[1] M. A. Ramdhani, H. Aulawi, A. Ikhwana, and Y. Mauluddin, "Model of green technology adaptation in small and medium-sized tannery industry,” J. Eng. Appl. Sci., vol. 12, no. 4, pp. 954-962, 2017.

[2] A. Faroqi, F. Zaelani, R. Kariadinata, and M. A. Ramdhani, "On the Design of Array Microstrip Antenna with SBand Frequency for Radar Communication,” in IOP Conference Series: Materials Science and Engineering, 2018, vol. 288 , no. 1 , p. 012006.

[3] A. Faroqi, M. A. Ramdhani, D. D. Andika, and S. Soedarsono, "Design of 2.75-2.85 Ghz Frequency Microstrip Band Pass Filter with Square Open-Loop Resonator in Radar Method,” Int. J. Eng. Technol., vol. 7, no. 2.29, pp. 711-715, 2018.

[4] L. Kamelia, M. A. Ramdhani, A. Faroqi, and V. Rifadiapriyana, "Implementation of Automation System for Humidity Monitoring and Irrigation System," in IOP Conference Series: Materials Science and Engineering, 2018, vol. 288, no. 1, p. 012092.

[5] M. Essahafi and M. A. Lafkih, "Microclimate Control of a Greenhouse by Adaptive Generalized Linear Quadratic Strategy," Indones. J. Electr. Eng. Comput. Sci., vol. 11, no. 1, pp. 377-385, 2018.

[6] N. Fajrin, I. Taufik, N. Ismail, L. Kamelia, and M. A. Ramdhani, "On the Design of Watering and Lighting Control Systems for Chrysanthemum Cultivation in Greenhouse Based on Internet of Things," IOP Conf. Ser. Mater. Sci. Eng., vol. 288, no. 1, p. 012105, 2018.

[7] S. Yahya, "Desain Otomasi Sistem Pengendalian Suhu dan Kelembapan Greenhouse," Bandung, 2011.

[8] Ekanantari, Outlook Komoditi Krisan. Jakarta: Pusat Data dan Sistem Informasi Pertanian, Kementerian Pertanian, 2014.

[9] L. Gao, M. Cheng, and J. Tang, "A Wireless Greenhouse Monitoring System based on Solar Energy," TELKOMNIKA, vol. 11, no. 9, pp. 5448-5454, 2013.

[10] M. K. I. A. Rahman, M. S. Z. Abidin, S. Buyamin, and M. S. A. Mahmud, "Enhanced fertigation control system towards higher water saving irrigation,” Indones. J. Electr. Eng. Comput. Sci., vol. 10, no. 3, pp. 859-866, 2018.

[11] R. Syam, Dasar-dasar Teknik Sensor. Makasar: Universitas Hasanuddin, 2013. 
[12] V. V. Verdi, "Desain dan Implementasi Sistem Pengukuran Kelembaban Tanah Menggunakan SMS Gateway Berbasis Arduino," Bandung, 2012.

[13] M. H. Widarto, "Aplikasi Pengatur Lampu Lalu Lintas Berbasis Arduino Mega 2560 Menggunakan Light Dependent Resistor (LDR) dan Laser," Jakarta, 2014.

[14] A. H. Saptadi, "Rancang Bangun Thermohygrometer Digital Menggunakan Sistem Mikropengendali Arduino dan Sensor DHT22," Purwokerto, 2016.

[15] B. Sudaryanto, Budidaya Tanaman Krisan. Jogyakarta: Balai Pengkajian Teknologi Pertanian, 2006.

[16] H. Oubehar et al., "High-order sliding mode control of greenhouse temperature," Indones. J. Electr. Eng. Comput. Sci., vol. 4, no. 3, pp. 548-554, 2016.

[17] T. Marsela, R. S. Sadjad, and A. Achmad, "Sistem Kendali Intensitas Cahaya Rumah Kaca Cerdas pada Budidaya Bunga Krisan," Makasar, 2013. 